\title{
Facilitation of long-delay conditioned taste aversion in weanling rats
}

\author{
PHILIPP J. KRAEMER \\ University of Kentucky, Lexington, Kentucky \\ JAMES S. MILLER and JOYCE A. JAGIELO \\ Edinboro University of Pennsylvania, Edinboro, Pennsylvania \\ and \\ NORMAN E. SPEAR \\ State University of New York, Binghamton, New York
}

\begin{abstract}
The impact of prior odor or taste conditioning on long-delay conditioned taste aversion in weanling rats was examined in two experiments. In Experiment 1, target conditioning consisted of saccharin paired $1.5 \mathrm{~h}$ later with an injection of $\mathrm{LiCl}$. Weanlings given an odor or a different taste paired immediately with $\mathrm{LiCl}$ prior to long-delay conditioning showed significantly stronger saccharin aversions than did subjects exposed to the odor or taste unpaired with $\mathrm{LiCl}$. The results of Experiment 2 indicated that the delay facilitation was not the result of any residual effect of $\mathrm{LiCl} ; \mathrm{LiCl}$ alone the day before delay conditioning did not enhance conditioned saccharin aversions. The results are discussed with respect to maturational and experiential interpretations of age-related differences in transfer of training and short-term memory.
\end{abstract}

Despite evidence that the immature rat possesses an impressive ability to learn (e.g., Gemberling \& Domjan, 1982; Johanson \& Hall, 1984; Rudy \& Cheatle, 1979), its relative cognitive status becomes more effective for most purposes over the first 8 weeks of life (Kail \& Spear, 1984; Spear \& Campbell, 1979; for a general review, see Spear \& Rudy, 1991). This developmental pattern often appears as better performance on learning and memory tasks by adults than by younger rats (Amsel, 1986; Spear \& Campbell, 1979), although some important exceptions should be noted (Spear \& Molina, 1987). This behavioral trend roughly parallels the functional development of the rat's brain and nervous system (Campbell \& Spear, 1972). It is reasonable, therefore, that explanations of age-related differences in learning and memory have emphasized the correlation between neurological maturation and cognitive proficiency (Amsel, 1986; Bachevalier \& Mishkin, 1984). It is also understandable why behavioral deficits in the infant rat have often been attributed to functional underdevelopment of the nervous system (Nadel \& ZolaMorgan, 1984; Nicolle, Barry, Veronesi, \& Stanton, 1989).

Many of the relative cognitive deficits expressed by immature rats obviously fit within a failed-mechanism perspective, but it is also reasonable to expect experience to

\footnotetext{
This research was supported by a grant from the National Institute of Mental Health (1R01 MH35219) to N.E.S. and a grant from the University of Kentucky Research Foundation to P.J.K. N. E. Spear is at the Center for Developmental Psychobiology, SUNY-Binghamton. Correspondence should be addressed to P. J. Kraemer, Department of Psychology, University of Kentucky, Lexington, KY 40506.
}

play an important role. For instance, age-related increases in exposure to an increasingly large set of stimulus values and stimulus dimensions might lead to corresponding differences in perceptual organization, representational content, and retrieval effectiveness (Gordon, 1979; Spear, Kraemer, Molina, \& Smoller, 1988).

An area in which it is particularly tempting to overlook the role of experience is in retention after short intervals, sometimes referred to as short-term memory (STM). One form of STM involves the retention of information that temporarily guides behavior. Examples of this form of STM would include retention of arm choices on a radialarm maze, delayed alternation, and reward-contingent response patterning (Capaldi, Miller, \& Nawrocki, 1986; Olton \& Samuelson, 1976). Another form of STM involves the retention of information that is to be associated at some later time with some other event. This form of STM is exemplified by long-delay conditioned taste aversion (CTA), in which the animal must associate the memory of a taste with an aversive drug experience that $\alpha$ curs after an extended retention interval.

Although not extensively studied, there is some evidence that younger rats are generally less proficient than adults on various STM tasks (Green \& Stanton, 1989; Miller, Jagielo, \& Spear, 1989; Rausch \& Raskin, 1984; Stanton, 1982). It is intuitively appealing to identify the locus of this age-related difference as the underdevelopment of relevant brain structures. For example, the rat hippocampus undergoes a major maturational change over the first 25 days after birth (Altman \& Bayer, 1975). A considerable amount of research with adults has established the importance of this structure for some forms of 
STM (Olton, Becker, \& Handlemann, 1979), and thus it seems only reasonable to expect that infant rats will be less proficient than adults on STM tasks that implicate the hippocampus (Green \& Stanton, 1989).

The same rationale is applicable to age-related differences in long-delay CTA. Although CTA can be established in adult rats over considerable delay periods, the strength of such conditioning is usually weaker than when the taste and the drug consequence are more temporally contiguous (Garcia, Hankins, \& Rusiniak, 1974). There is some evidence that younger rats are disrupted even more than adults by long delays imposed between taste and drug experiences (Steinert, Infurna, Jardula, \& Spear, 1979). A reasonable hypothesis is that this ontogenetic difference corresponds to an age-related difference in the functional maturity of relevant brain structures necessary for long-delay learning. What needs to be considered, however, is to what degree experience may also be involved.

It has been shown in adults that a prior taste-drug experience can alleviate a deficit otherwise found with longdelay CTA. Westbrook and Homewood (1982) found that delays of $1.5 \mathrm{~h}$ or more between taste and drug reduced the strength of a conditioned taste aversion in adults, relative to a contiguous taste-drug pairing. This effect was eliminated, however, when long-delay conditioning was preceded by a nondelay conditioning episode, in which a different flavor from that used in the long-delay training was paired with an immediate injection of $\mathrm{LiCl}$. This effect was shown to be associative in nature and was not the result of simple generalization across the two flavors.

\section{EXPERIMENT 1}

In this experiment, we examined whether a facilitation of long-delay CTA appears in immature rats (19 days of age at conditioning). Prior research established that in some situations younger rats express stronger intermodal transfer of training than do adults (Spear \& Molina, 1987). Especially relevant to the present experiment are data indicating that weanlings, but not adults, express stronger CTAs when they have previously been exposed to an odor paired with the same drug and drug intensity subsequently used to condition a taste aversion (Kraemer, Kraemer, Smoller, \& Spear, 1989). What is not known is whether this type of transfer of training would also have a mitigating impact on long-delay CTA in immature rats. Equally interesting is whether prior taste conditioning will eliminate a long-delay effect in preweanlings, as has been found in adults (Westbrook \& Homewood, 1982).

\section{Method}

Subjects. All subjects were born and reared in the colony at SUNY-Binghamton. The 66 weanlings were taken from eight different litters. Litter size is systematically maintained at between 8 and 10 pups by culling within $24 \mathrm{~h}$ after birth. The weanlings were separated from the dam and water-deprived at postnatal Day 19. Littermates were group housed in plastic maternity cages filled with clean pine shavings. Weanlings within each litter were randomly assigned to the six groups $(n=11)$. Standard rat chow was available on the floor of each maternity cage, unless otherwise indicated. The rats were maintained in a climate-controlled vivarium, which operated on a 16:8-h light:dark cycle. All testing occurred during the lights-on period.

Apparatus. Training and testing were conducted in stainless steel hanging cages, attached to a cage rack that holds 30 cages. Cage racks were located in two identical test rooms. Newspapers were placed on trays underneath each row of cages. Liquids were dispensed through graduated glass cylinders $(50 \mathrm{ml})$ attached to the front of each cage. The two odors consisted of commercial brands of artificial banana extract (Virginia Dare) and lemon oil (Humco). The two flavors consisted of $.15 \%$ saccharin and $2 \%$ chocolate milk (diluted $50 \% \mathrm{w} / \mathrm{v}$ with water). Drug administrations consisted of IP injections of $.3 \mathrm{M} \mathrm{LiCl}$, given at a $1 \%$ body-weight dose level.

Odor preference tests were conducted in a clear Plexiglas chamber $(28 \times 11 \times 12 \mathrm{~cm})$ fitted with a wire-mesh floor. The odors were placed on cotton underneath the wire-mesh floor; banana was placed at one end and lemon at the other end.

Procedure. Experimental testing was completed over a 4-day period, as outlined in Table 1 . On Day 1 , all subjects received tap water in the test cage for $30 \mathrm{~min}$ and were then returned to their home cages. Groups B-S+ and $\mathbf{M}-\mathbf{S}+$ received $\mathrm{LiCl}$ injections $5 \mathrm{~h}$ after water exposure. These subjects were isolated in clean maternity cages filled with pine shavings for $4 \mathrm{~h}$ after injection, after which they were returned to their littermates. The remaining subjects were injected with saline.

On Day 2, all subjects were exposed to the test cage for $2.5 \mathrm{~h}$. The subjects in Groups B-S + and B $+\mathrm{S}+$ had $2 \mathrm{ml}$ of banana extract placed on newspaper directly below the floor of their test cages. They were given an injection of either $\mathrm{LiCl}$ (Group $\mathrm{B}+\mathrm{S}+$ ) or saline (Group B-S+) $30 \mathrm{~min}$ after exposure to the banana odor, after which they were returned to the test cage for an additional $2 \mathrm{~h}$. The subjects in Groups $\mathbf{M}-\mathbf{S}+$ and $\mathbf{M}+\mathbf{S}+$ were placed in test cages without banana odor, but with a drinking bottle present that contained chocolate milk. The chocolate milk was removed after $30 \mathrm{~min}$, and each subject then received an injection of either $\mathrm{LiCl}$ (Group $\mathbf{M}+\mathbf{S}+$ ) or saline (Group $\mathbf{M}-\mathbf{S}+$ ), followed by replacement in the test cage for an additional $2 \mathrm{~h}$. The subjects in Groups $S+$ and $S-$ were exposed to the test cage in the absence of banana odor or chocolate milk. Thirty minutes after placement in the test cage, these subjects were injected with saline and returned to the test cage for an additional $2 \mathrm{~h}$. All subjects were returned to their respective home cages immediately after the 2.5 -h exposure period of Phase 1.

On Day 3, all subjects received $30 \mathrm{~min}$ of exposure in the test cage to a drinking bottle that contained saccharin, after which they were returned to home cages that did not contain food. The subjects in Group $\mathrm{S}$ - received an injection of saline, and the remaining subjects received an injection of $\mathrm{LiCl}$ after a 1.5-h delay. Food was replaced after an additional $2 \mathrm{~h}$. A taste preference test was given $24 \mathrm{~h}$ later. All subjects received $30 \mathrm{~min}$ of exposure in the test cage to two drinking bottles, one containing saccharin and the

Table 1

General Experimental Design and Training Procedure Used in Experiment 1

\begin{tabular}{|c|c|c|c|c|}
\hline Group & Day 1 & Day 2 & Day 3 & Day 4 \\
\hline $\begin{array}{l}\mathrm{B}+\mathrm{S}+ \\
\mathrm{B}-\mathrm{S}+\end{array}$ & $\begin{array}{l}\text { Saline } \\
\text { LiCl }\end{array}$ & $\begin{array}{l}\text { B + LiCl } \\
\text { B + Saline }\end{array}$ & $\begin{array}{l}\text { S Delay* } \mathrm{LiCl} \\
\text { S Delay } \mathrm{LiCl}\end{array}$ & $\begin{array}{l}\text { Test } \\
\text { Test }\end{array}$ \\
\hline $\begin{array}{l}\mathbf{M}+\mathbf{S}+ \\
\mathbf{M}-\mathbf{S}+\end{array}$ & $\begin{array}{l}\text { Saline } \\
\text { LiCl }\end{array}$ & $\begin{array}{l}\mathbf{M}+\mathbf{L i C l} \\
\mathbf{M}+\text { Saline }\end{array}$ & $\begin{array}{ll}\text { S Delay } & \mathrm{LiCl} \\
\text { S Delay } & \mathrm{LiCl}\end{array}$ & $\begin{array}{l}\text { Test } \\
\text { Test }\end{array}$ \\
\hline $\begin{array}{l}S+ \\
S-\end{array}$ & $\begin{array}{l}\text { Saline } \\
\text { Saline }\end{array}$ & $\begin{array}{l}\text { Saline } \\
\text { Saline }\end{array}$ & $\begin{array}{ll}\text { S Delay } & \mathrm{LiCl} \\
\text { S Delay } & \text { Saline }\end{array}$ & $\begin{array}{l}\text { Test } \\
\text { Test }\end{array}$ \\
\hline
\end{tabular}

Note-B = banana odor; $M=$ chocolate milk; $S=$ saccharin. $\quad$ *The delay on Day 3 was $1.5 \mathrm{~h}$. 
other containing tap water. The amount of each liquid consumed during the test session was recorded to the nearest $.10 \mathrm{ml}$.

The subjects in Groups $\mathrm{B}+\mathrm{S}+$ and $\mathrm{B}-\mathrm{S}+$ were given a spatialodor preference test between the banana and lemon odors $24 \mathrm{~h}$ after the taste preference test. Each subject was placed facing a side wall at the center line that separated the test chamber into two equal halves. Location of the snout during the test period determined the side of the test chamber that the rat was occupying. An observer recorded the time spent on the banana side of the chamber during a 3-min test period.

\section{Results and Discussion}

Consumption levels for the six groups on the conditioning day indicated that there were no significant differences in amount of saccharin consumed between preexposed groups (Groups $\mathbf{B}-\mathbf{S}+, \mathrm{B}+\mathbf{S}+, \mathbf{M}-\mathbf{S}+$, and $\mathbf{M}+\mathbf{S}+$ ) and nonpreexposed groups (Groups $S+$ and $S-$ ). These results suggest that there was no generalized aversion to saccharin expressed by groups previously given $\mathrm{LiCl}$ paired or unpaired with banana odor or chocolate milk.

A percent saccharin preference score was computed for each subject according to the following: amount of saccharin drunk/total amount of saccharin and water drunk. Mean percent saccharin preference scores for each of the six groups are presented in Figure 1. The most notable aspect of these data is that groups given either chocolate milk (Group $\mathbf{M}+\mathbf{S}+$ ) or banana odor (Group $\mathrm{B}+\mathrm{S}+$ ) paired with $\mathrm{LiCl}$ prior to long-delay conditioning showed much lower saccharin preference scores than did the remaining four groups. It is also evident that preference scores for weanlings given saccharin and $\mathrm{LiCl}$ after a long delay were not much different from those of the conditioning control group (Group $S-$ ), which received saccharin paired with saline. A one-way analysis of variance (ANOVA) confirmed these observations. Saccharin preferences differed significantly across the six groups $[F(5,60)=20.6, p<.001]$. Individual group mean comparisons (Fisher's least significant difference test; Kep-

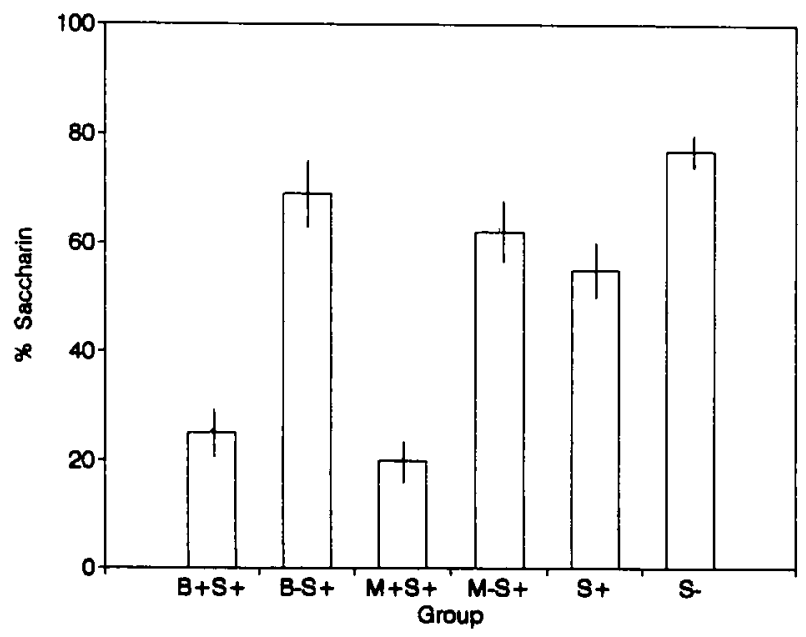

Figure 1. Mean percent seccharin preference scores for weanling rats tested in Experiment 1. Lines at the top of the bars denote standard errors. pel, 1991) indicated that preference scores were significantly lower in Groups $\mathrm{B}+\mathrm{S}+$ and $\mathrm{M}+\mathrm{S}+$ than in each of the remaining four groups; saccharin preference scores did not differ significantly between the former two groups or among the latter four groups.

Results of the spatial-odor preference test indicated that weanlings in Group $B+S+(X=58.9 \mathrm{sec})$ spent significantly less time over banana odor than did weanlings in Group B-S + [X=104.2 sec, $t(20)=4.4, p<.01]$. Thus, an odor aversion appeared when banana was paired with $\mathrm{LiCl}$, but not when banana and $\mathrm{LiCl}$ were unpaired.

The results indicate that long-delay CTA can be facilitated in weanlings by preexposure to either an odor or a taste paired immediately with $\mathrm{LiCl}$. The absence of facilitation in subjects given exposure to an odor or a taste unpaired with $\mathrm{LiCl}$ indicates that the occurrence of facilitation is not due merely to stimulus preexposure or prior experience with $\mathrm{LiCl}$. It is also clear that weanlings were profoundly affected by the long delay imposed between saccharin exposure and injection of $\mathrm{LiCl}$. Unless exposed to an odor or a different taste immediately paired with $\mathrm{LiCl}$, weanlings exhibited a preference for saccharin equivalent to that shown by a group given saccharin paired with saline.

In addition to establishing evidence that long-delay CTA in weanlings is influenced by prior experience, the current findings also extend the range of transfer-of-training effects that have now been observed in immature rats (Spear \& Molina, 1987; Spear et al., 1988). In the case of odor preexposure, we also showed that the transfer effect with delay CTA depends on the establishment of an odor aversion; exposure to an odor or taste unpaired with $\mathrm{LiCl}$, which is insufficient to produce a conditioned aversion to the odor, fails to enhance long-delay CTA in weanlings. That the enhancement in long-delay learning was comparable with either prior odor conditioning or prior taste conditioning suggests further that whatever process is responsible for this facilitation of long-delay conditioning, it is functionally equivalent in weanlings given olfactory or gustatory cues.

The facilitation produced by odor conditioning, however, implies that primary stimulus generalization does not seem to be a likely mechanism for interpreting the enhanced-delay CTA. The intermodal differences between a banana odor and a saccharin flavor would seem to minimize the opportunity for the subject to generalize the odor conditioning to saccharin. More important, the absence of a difference between preexposed and nonpreexposed subjects in the consumption of saccharin during long-delay conditioning implies that neither a prior odor aversion nor taste aversion generalized to saccharin. Consistent with that result is the absence of evidence for immediate transfer in immature rats. A conditioned reaction to one stimulus has led to no more than a borderline conditioned reaction to an untrained stimulus from another dimension, and usually there is no such transfer unless the two stimuli have a common associate (Spear \& Molina, 1987; Spear et al., 1988). 


\section{EXPERIMENT 2}

The results of Experiment 1 indicated that prior exposure to an odor or taste temporally paired with $\mathrm{LiCl}$ can facilitate long-delay CTA in weanlings; unpaired presentations of an odor or a taste with $\mathrm{LiCl}$, however, does not affect long-delay CTA. Thus, it appears that longdelay facilitation in weanlings is associative in nature, but there is a minor procedural detail that could undermine that conclusion.

Drug USs, unlike proprioceptive USs such as footshock, produce effects that extend over long intervals and involve motivational consequences. The backward pairing used in Experiment 1 was intended to provide the control groups with the same exposure to the CS and US as given to the experimental groups, but in a temporally noncontiguous fashion. This procedure, however, confounds the duration between $\mathrm{LiCl}$ injections with whether the $\mathrm{CS}$ and US in Phase 1 were paired or unpaired. It is therefore possible that the facilitation effect obtained in the groups given paired CS-US exposure in Phase 1 was due in part to the residual effects of $\mathrm{LiCl}$; paired groups received their first $\mathrm{LiCl}$ injections $24 \mathrm{~h}$ before receiving their second injections, whereas $\mathrm{LiCl}$ injections in unpaired groups were separated by $48 \mathrm{~h}$.

In Experiment 2, we included a US-alone group that received $\mathrm{LiCl}$ alone in Phase $1,24 \mathrm{~h}$ before delay conditioning in Phase 2. We also included a group that received $\mathrm{LiCl}$ alone in Phase 1, but then in Phase 2 received saccharine and $\mathrm{LiCl}$ paired without delay. The performance of the latter group allowed us to evaluate the facilitation effect relative to nondelay conditioning. Given the comparable facilitation produced by odor and taste conditioning in Experiment 1, we simplified our procedure by using only an odor-conditioning experimental group. By omitting a group given taste paired with $\mathrm{LiCl}$ in Phase 1 , we were able to equate liquid consumption across the three groups during Phase 1: all groups drank water, and at the same time of day, before Phase 2.

\section{Method}

We used the same type of apparatus and general test procedure as in Experiment 1. Subjects were 32 weanlings taken from the colony at the University of Kentucky. All animal-maintenance procedures were the same as those followed at SUNY-Binghamton. Subjects from each of four litters were randomly assigned to three groups $(n=8)$. Group BS Del received exposure to banana odor paired immediately with $\mathrm{LiCl}$ during Phase 1 and $24 \mathrm{~h}$ later received a 1.5-h delayed pairing of saccharin and $\mathrm{LiCl}$ in Phase 2. Groups $\mathrm{S}$ and $\mathrm{S}$ Del received $\mathrm{LiCl}$ in Phase 1 and $24 \mathrm{~h}$ later were exposed to saccharin followed by $\mathrm{LiCl}$, given either immediately after saccharin termination (Group S) or after a 1.5-h delay (Group S Del). A two-bottle saccharin preference test was administered $24 \mathrm{~h}$ after Phase 2.

\section{Results and Discussion}

Mean percent saccharin preference scores are presented in Figure 2. It can be seen that saccharin preferences were similar in Groups BS Del and S and were substantially lower in these two groups than in Group S Del. Statisti-

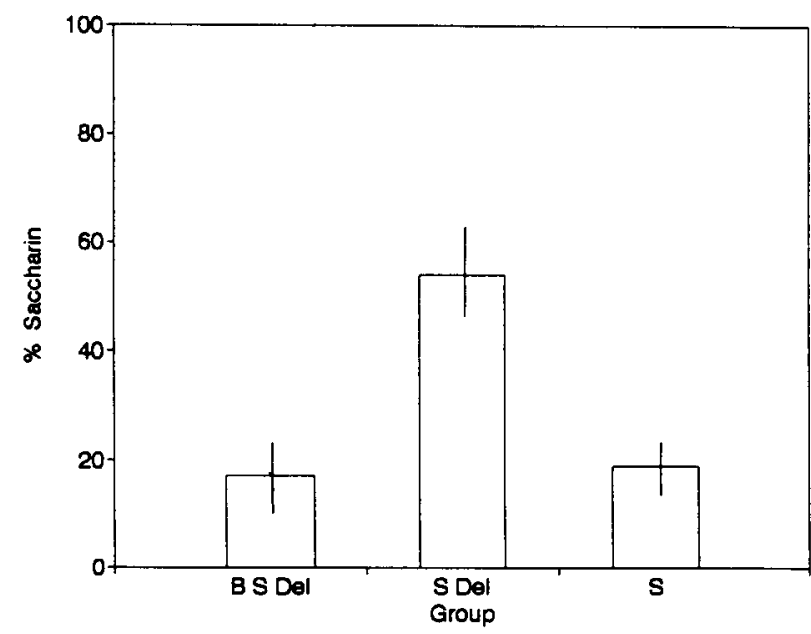

Figure 2. Mean percent saccharin preference scores for weanling rats tested in Experiment 2. Lines at the top of the bars denote standard errors.

cal analyses confirmed these observations. Significant differences were found in the mean saccharin preferences over the three groups $[F(2,21)=11.43, p<.001]$. Post hoc comparisons further revealed that preferences were equivalent in Groups BS Del and S and significantly lower than those in Group S Del. These results replicate the delay-facilitation effect found with odor conditioning in Experiment 1 and also indicate that a $\mathrm{LiCl}$ injection alone the day before delay conditioning is insufficient to produce a facilitation in delay CTA in weanlings. Finally, the equivalent saccharin preferences shown by Groups BS Del and $S$ indicate that prior odor conditioning can facilitate delay CTA to a point comparable to what performance would be without the 1.5-h delay.

\section{GENERAL DISCUSSION}

The important new finding that emerged from this study is that long-delay CTA can be facilitated in weanling rats by prior conditioning. This effect parallels what has been found in adult rats (Westbrook \& Homewood, 1982). When given either an odor (banana) or a taste (chocolate milk) immediately paired with $\mathrm{LiCl}$, weanlings subsequently showed an enhanced saccharin aversion following a procedure in which saccharin was separated from $\mathrm{LiCl}$ injection by $1.5 \mathrm{~h}$. When banana and chocolate milk were unpaired with $\mathrm{LiCl}$, facilitation in long-delay learning did not appear. Delay facilitation does not appear to depend on any residual effect of $\mathrm{LiCl}$ given during the first phase of training; subjects given $\mathrm{LiCl}$ alone the day before delay conditioning did not show facilitation. Thus, we conclude that a taste- or odor-drug association (direct evidence of the latter was obtained in Experiment 1) facilitates subsequent long-delay CTA in weanlings.

These results have important implications for a developmental analysis of brain-behavior relations. It is clear that 
weanlings show a significant delay deficit when saccharin and $\mathrm{LiCl}$ are temporally separated. The data suggest, however, that the delay deficit can be obviated. Thus, it does not appear that weanlings lack the brain mechanism necessary to bridge an extended delay, at least within the context of the CTA procedure. How that mechanism is influenced by prior learning can only be speculated, but there is comparative evidence that human STM is also dramatically affected by the subject's cumulative experience (Chase \& Simon, 1973; Dempster, 1978). It is unlikely, therefore, that STM capacity is entirely fixed neurophysiologically, although experiential modification of this retention may have a quite different basis in humans and other animals.

Another important implication of these results relates to transfer of training effects that have been found with immature rats. Weanling and preweanling rats often exhibit stronger intermodal transfer of training than do adults. This general effect has appeared in several forms. One example involves the greater likelihood that infant rats will consume alcohol if they have been preexposed to the odor of alcohol, an effect that adults do not show (Molina, Serwatka, \& Spear, 1984; Molina, Serwatka, Spear, \& Spear, 1985). Infant rats also tend, for instance, to show stronger conditioning to a visual cue if they have been previously conditioned with an odor paired with the same US, or vice versa; this effect does not appear in adults (Spear \& Molina, 1987). Finally, weanlings, but not adults, show stronger CTA when they are first trained with an odor paired with the same drug used to condition an aversion to the taste (Kraemer et al., 1989). The present results establish yet another instance of transfer in the immature rat, involving both intermodal (odor to taste transfer) and interdimensional (taste to taste transfer) cues.

The mechanism responsible for transfer effects in the infant rat remains unknown, although several alternatives have been proposed. One possibility is that immature rats are more inclined to equate stimuli that provide the same affordance (Spear et al., 1988). For example, when an odor and a taste have been paired with the same dose of a drug, the two signals may become functionally equivalent as a consequence of their shared meaning, that is, they both signal the same aversive event. When taste conditioning is preceded by odor conditioning, it is as if the infant equates the odor and taste to the extent that it regards the two episodes as a repetition of the same event (signal + drug) and ignores the stimulus properties that differentiate odors and tastes because each stimulus has been associated with the same consequence.

Another possibility is that the locus of the transfer effect is at the perceptual level. Immature rats may perceive stimuli in terms of amodal characteristics, as opposed to the strategy employed by adults of attending to stimulusspecific properties (Kraemer \& Spear, 1990). It has been suggested that subjective intensity may be one of the fundamental amodal attributes used by infant rats to respond to stimuli (Turkewitz, Gardner, \& Lewkowicz, 1984), and it is possible that infant rats equate the subjective intensity of stimuli from different modalities (Kraemer \& Spear, 1990; Mellon, Kraemer, \& Spear, 1991; Turkewitz \& Mellon, 1989). This type of perceptual identification could lead the infant to define particular odors and tastes as being the same event. This hypothesis would predict, however, that prior conditioning would produce immediate transfer, in terms of generalization along an intensity gradient. Immediate or direct transfer was not obtained in Experiment 1 (e.g., weanlings trained with an odor paired with $\mathrm{LiCl}$ did not express an aversion to saccharin, based on consumption data from the target conditioning session). Consistent with other findings from transfer studies (Spear \& Molina, 1987), our results suggest that some other mechanism is involved. The identification of that mechanism awaits additional research.

\section{REFERENCES}

Altman, J., BAyer, S. (1975). Postnatal development of the hippocampal dentate gyrus under normal and experimental conditions. In R. Issacson \& K. H. Pribram (Eds.), The hippocampus (Pt. 1, pp. 95122). New York: Plenum.

AMSEL, A. (1986). Developmental psychobiology and behavior theory: Reciprocating influences. Canadian Journal of Psychology, 40, 311-342.

Bachevalier, J., Mishkin, M. (1984). An early and a late developing system for learning and retention in infant monkeys. Behavioral Neuroscience, 98, 770-778.

Campbell, B. A., Spear, N. E. (1972). Ontogeny of memory. Psychological Review, 79, 215-236.

Capaldi, E. J., Miller, D. J., Nawrocki, T. M. (1986). Retention interval and intertrial interval in a serial learning or delayed discrimination task. Joumal of Experimental Psychology: Animal Behavior Processes, 12, 59-68.

Chase, W. G., a Simon, H. A. (1973). Perception in chess. Cognitive Psychology, 4, 55-81.

Dempster, F. N. (1978). Memory span and short-term memory capacity: A developmental study. Journal of Experimental Child Psychology, 26, 419-431.

Garcia, J., Hankins, W. G., \& Rusiniak, K. W. (1974). Behavioral regulation of the milieu interne in man and rat. Science, 185, 824-831.

Gemberung, G. A., \& Doman, M. (1982). Selective associations in one-day-old rats: Taste-toxicosis and texture-shock aversion learning. Joumal of Comparative \& Physiological Psychology, 96, 105-113.

Gordon, W. C. (1979). Age: Is it a constraint on memory content? In N. E. Spear \& B. A. Campbell (Eds.), Ontogeny of learning and memory (pp. 271-287). Hillsdale, NJ: Erlbaum.

GREEN, R. J., \& StANToN, M. E. (1989). Differential ontogeny of working memory and reference memory in the rat. Behavioral Neuroscience, 103, 98-105.

Johanson, I. B., HALL, W. G. (1984). Ontogeny of appetitive learning: Independent ingestion as a model motivational system. In R. Kail \& N. E. Spear (Eds.), Comparative perspectives on the development of memory (pp. 135-157). Hillsdale, NJ: Erlbaum.

KAIL, R., a SPEAR, N. E. (EDs.) (1984). Comparative perspectives on the development of memory. Hillsdale, NJ: Erlbaum.

KePpel, G. (1991). Design and analysis. Englewood Cliffs, NJ: Prentice-Hall.

Kraemer, P. J., Kraemer, E. G., Smoller, D. E., \& Spear, N. E. (1989). Enhancement of flavor aversion conditioning in weanling but not adult rats by prior conditioning to an odor. Psychobiology, 17, 34-42.

Kraemer, P. J., Spear, N. E. (1990). Preweanling and adult rats treat conditioned light-tone combinations differently. Animal Learning \& Behavior, 18, 113-123. 
Mellon, R. C., Kraemer, P. J., \& Spear, N. E. (1991). Development of intersensory function: Age-related differences in stimulus selection of multimodal compounds in rats as revealed by Pavlovian conditioning. Joumal of Experimental Psychology: Animal Behavior Processes, 17, 448-464.

Miller, J. S., Jagielo, J. A., Spear, N. E. (1989). Age-related differences in short-term retention of separable elements of an odor aversion. Journal of Experimental Psychology: Animal Behavior Processes, 15, 194-201.

Molina, J. C., Serwatka, J., \& Spear, N. E. (1984). Changes in alcohol intake resulting from prior experience with alcohol odor in young rats. Pharmacology, Biochemistry, \& Behavior, 21, 387-391.

Molina, J. C., Serwatka, J., Spear, L., \& Spar, N. (1985). Differential ethanol olfactory experiences affect ethanol ingestion in preweanlings but not in older rats. Behavioral \& Neural Biology, 44, 90-100.

NADEL, L., \& Zola-Morgan, S. (1984). Infantile amnesia: A neurobiological perspective. In M. Moscovitch (Ed.), Infant memory (pp. 145172). New York: Plenum.

Nicolle, M. M., Barry, C. C., Veronesi, B., Stanton, M. E. (1989). Fornix transections disrupt the ontogeny of latent inhibition in the rat. Psychobiology, 17, 349-357.

Olton, D. S., Becker, J., Handelmann, G. (1979). Hippocampus, space and memory. Behavioral Brain Sciences, 2, 313-365.

Olton, D. S., SAmuelson, R. J. (1976). Remembrance of places passed: Spatial memory in rats. Journal of Experimental Psychology: Animal Behavior Processes, 2, 97-116.

RAusCh, S., \& RASKTN, L. (1984). Cholinergic mediation of spatial memory in the preweanling rat: Application of the radial arm maze paradigm. Behavioral Neuroscience, 98, 35-43.

Rudy, J. W., Cheatle, M. D. (1979). Ontogeny of associative learning: Acquisition of odor aversions by neonatal rats. In N. E. Spear \& B. A. Campbell (Eds.), Ontogeny of leaming and memory (pp. 157188). Hillsdale, NJ: Erlbaum.

Spear, N. E., \& Campbell, B. A. (Eds.) (1979). Ontogeny of leaming and memory. Hillsdale, NJ: Erlbaum.
Spear, N. E., Kraemer, P. J., Molina, J. C., \& Smoller, D. E. (1988). Developmental change in learning and memory: Infantile disposition for unitization. In J. Delcour \& C. S. Levy (Eds.), Systems with leaming and memory abilities (pp. 27-52). Amsterdam: Elsevier North-Holland.

SPEAR, N. E., Molina, J. C. (1987). The role of sensory modality in the ontogeny of stimulus selection. In N. A. Krasnegor, E. M. Blass, M. A. Hoffer, \& W. P. Smotherman (Eds.), Perinatal development: A psychobiological perspective (pp. 83-110). Orlando: Academic Press.

SPEAR, N. E., \& RUdy, J. W. (1991). Tests of the ontogeny of learning and memory: Issues, methods, and results. In H. N. Shair, G. A. Barr, \& M. A. Hoffer (Eds.), Developmental psychobiology: Methods and changing concepts (pp. 84-113). London: Oxford University Press. Steinert, P. A., Infurna, R. N., Jardula, M. F., SPear, N. E. (1979). Effects of CS concentration on long-delay taste aversion learning in preweanling and adult rats. Behavioral \& Neural Biology, 27, 487-502.

Stanton, M. (1982). Performance of 11- and 14-day-old rats on a working memory problem. Behavioral \& Neural Biology, 36, 304-310.

Turkewitz, G., GARDNER, J. M., \& Lewkowicz, D. J. (1984). Sensory/perceptual functioning during early infancy: The implications of a quantitative basis for responding. In G. Greenberg \& E. Tobach (Eds.), Behavioral evolution and integrative levels (pp. 167-195). Hillsdale, NJ: Erlbaum.

TURKewitz, G., Mellon, R. C. (1989). Dynamic organization of intersensory function. Canadian Journal of Psychology, 43, 286-301.

WeSTBRoOK, R. F., HomewOOd, H. (1982). The effects of a flavourtoxicosis pairing upon long-delay, flavour aversion learning. Quarterly Joumal of Experimental Psychology, 34B, 59-75.

(Manuscript received July 22, 1991; revision accepted for publication April 7, 1992.) 